\title{
Article
}

\section{Change management: The case of the elite sport performance team}

Cruickshank, A., and Collins, D.

Available at http://clok.uclan.ac.uk/5571/

Cruickshank, A., and Collins, D. ORCID: 0000-0002-7601-0454 (2012) Change management: The case of the elite sport performance team. Journal of Change Management, 12 (2). pp. 209-229. ISSN 1469-7017

It is advisable to refer to the publisher's version if you intend to cite from the work. http://dx.doi.org/10.1080/14697017.2011.632379

For more information about UCLan's research in this area go to http://www.uclan.ac.uk/researchgroups/ and search for < name of research Group>.

For information about Research generally at UCLan please go to http://www.uclan.ac.uk/research/

All outputs in CLoK are protected by Intellectual Property Rights law, including Copyright law. Copyright, IPR and Moral Rights for the works on this site are retained by the individual authors and/or other copyright owners. Terms and conditions for use of this material are defined in the policies page.

\section{CLoK}

Central Lancashire online Knowledge www.clok.uclan.ac.uk

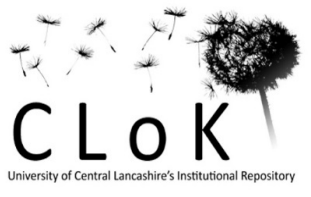


This is a pre-proof correct manuscript, as accepted for publication, of an article published by Taylor \& Francis in Journal of Change Management on $2^{\text {nd }}$ March 2012, available online: http://www.tandfonline.com/doi/abs/10.1080/14697017.2011.632379\#.VdsjuvlVhBc

PLEASE REFER TO THE PUBLISHED VERSION FOR CITING PURPOSES

Change Management: The Case of the Elite Sport Performance Team

Andrew Cruickshank \& Dave Collins

Institute of Coaching and Performance, University of Central Lancashire 


\begin{abstract}
The effective and efficient implementation of change is often required for both successful performance and management survival across a host of contemporary domains (By, Diefenbach and Klarner, 2008; Bamford and Daniel, 2005; Ruvolo and Bullis, 2003). However, while of major theoretical and practical significance (League Managers Association, 2010), research to date has overlooked the application of change management (hereafter CM) knowledge to the elite sport performance team environment. Considering that the success of 'off-field' sports businesses are largely dependent on the performances of their 'on-field' team, the present paper therefore explores the application of current CM theorising to this specific setting and the challenges facing its utility. Accordingly, we identify the need and importance of developing theory specific to this area, with practical application in both sport and business, through examination of present knowledge and identification of the domain's unique, dynamic and contested properties. Markers of successful change are then suggested to guide initial enquiry before the paper concludes with proposed lines of research which may act to provide a valid and comprehensive theoretical account of CM to optimise the research and practice of those working in the field.
\end{abstract}

Keywords: applied practice, complexity theory, decentred theory, framework, high performing culture 
Change management (hereafter $\mathrm{CM}$ ) has received considerable attention in organisational research as the quest to optimise performance continues (Stensaker and Langley, 2010). Conceptualised as “the process of continually renewing an organisation's direction, structure, and capabilities to serve the ever-changing needs of external and internal customers" (Moran and Brightman, 2001, p.111), it is not surprising that the construct is also of major theoretical and practical significance across a variety of domains such as health services (e.g., Bamford and Daniel, 2005), education services (By, Diefenbach and Klarner, 2008) and the military (Ruvolo and Bullis, 2003). One further environment where the management of change represents a highly critical and sought after skill is that of elite sport performance teams (Bruinshoofd and ter Weel, 2003). However, while a regularly undertaken, performance-determining process, there is a dearth of literature on the topic.

Indeed, resonating with the definition above, contemporary sports organisations must provide a constantly marketable product (i.e., results, entertaining performances, star players) to a set of highly demanding external stakeholders (e.g., fans, media, sponsors: Mielke, 2007) for the business to achieve its short and long-term aspirations. It is therefore imperative that the company is sensitive to the oscillating requirements of the system which delivers such prosperity-supporting outcomes: the on-field performance team (Gilmore and Gilson, 2007). However, unlike other domains, when a Board of Directors perceive that the functioning of this 'front-line' workforce is not sufficient for actualising the organisation's goals (i.e., normally through sub-standard performances), the development and deployment of solutions are not normally internally driven. Specifically, whereas CEO's may be afforded notable time to turn around the fortunes of underperforming organisational elements, a 'hiring and firing' policy is often employed when the manager/head coach of the on-field performance team fails to provide expected results (Bruinshoofd and ter Weel, 2003). Accordingly, in their efforts to attain the exponential rewards and prestige associated with on-field success 
(Gilmore and Gilson, 2007), elite sport organisations are now regularly engaged in quests to find a team manager whose CM programme can perpetuate beliefs, expectations and behaviours in players and support staff which support sustained optimal performance; in short, a high performing culture (personal communication with an English Premiership Director of Rugby, June 15, 2011).

Conversely, however, while CM aimed at the optimisation of culture is as a lengthy process (Price and Chahal, 2006), newly appointed managers also suffer from the same shortterm perspective which ended the tenure of their predecessors. For example, the current lifeexpectancy of team managers/head coaches in English league football stands at a record low of 1.4 years. Furthermore, if sacked from a first position, almost half are never then entrusted with another (League Managers Association, 2010). Recent work by Mielke (2007) also suggests that this phenomenon is not only a European matter and restricted to professional football, with top tier coaches across a range of sports in the United States also regularly replaced for failing to meet team owners' expectations. Accordingly, although the creation of high performing cultures has always been an implicit, ongoing agenda item of incoming elitelevel managers, head coaches and performance directors (Lee, Shaw and Chesterfield, 2009; Fletcher and Arnold, 2011; Potrac and Jones, 2009), the demand for immediate and sustained performance-enhancing change has elevated this CM task to a career-defining level. Further acknowledging the inherently stressful nature of the role (Olusoga et al., 2009; Thelwell et al., 2008), this lack of CM knowledge is therefore an urgent concern for the optimisation of elite team performance and the longevity of the incoming manager/head coach.

Although research in the wider sport field has recently turned attention to understanding the delivery of such change, investigation has thus far been located predominantly in sports company management, focusing on organisational aspects (e.g., Thibault and Babiak, 2005; Zakus and Skinner, 2008; Bloyce et al., 2008) rather than team 
performance per se. As evidence continues to support the notion that contemporary 'on-field' achievement can be strongly influenced by the success of the 'off-field' business (Guzmán, 2006; Smith and Stewart, 2010), this is a valuable line of enquiry. However, acknowledging that it is the performance team which ultimately delivers the decisive 'product', and which determines the longevity of the off-field system, gaining a conceptual and practical understanding of $\mathrm{CM}$ specific to this environment is vital for providing the platform upon which the organisation may flourish.

Indeed, as identified above, incoming managers (and their supporting consultants) have little domain-specific guidance for transforming an underperforming team culture. Accordingly, a number of critical questions remain both unconsidered and unanswered in this setting: for instance, how should the vision and implementation plans be created, established and disseminated? What systems, procedures and processes support a high performing culture? How and when should they be introduced, monitored and altered? And through what mechanisms can they be established and sustained? Recognising the functional similarities of the performance team manager/head coach and their business equivalent (Dawson and Dobson, 2002; Weinberg and McDermott, 2002) alongside the value of high performing cultures to both (Fletcher and Arnold, 2011; Kotter and Heskett, 1992), such an agenda may also proffer insightful and significant lessons for organisational research and practice. Indeed, recent knowledge exchange would suggest that this is highly likely. For example, contemporary work in sport psychology has highlighted the utility of 360-degree feedback (Cope et al., 2007) and organisational citizenship behaviour (Aoyagi et al., 2008) for creating optimal team environments. Conversely, business has previously taken lessons from sport, such as the construct of mental toughness (Jones, 2008). As such, beyond supporting the acquisition of theoretical and applied CM knowledge of and for elite sport 
performance teams, we also consider that organisational CM knowledge can in turn be enhanced through this focus (Collins, 2008).

Certainly, as a consequence of CM's roots in organisational settings, the majority of investigations have been focused on large scale businesses (Bamford and Forrester, 2003; Wissema, 2001) resulting in the development of theory and prescription shaped by the characteristics of organisational life. However, elite sport offers a unique environment in which to investigate the implications of the decisions and actions of change leaders at a more detailed, micro-level (cf., Cunningham, 2006a, 2006b). Specifically, in contrast to change in sizable organisations, where employees often have limited shared individual/group interests and minimal interaction with strategic management (Driscoll and Morris, 2001), managers and coaches of sports performers commonly lead far smaller numbers of individuals with both groups involved with each other's professional lives to an extent where success is highly dependent on the other (Jones and Wallace, 2005). Accordingly, as the measures and mechanisms of change are therefore experienced and interpreted in a significantly personal manner by the targets (i.e., performers and support staff), elite sport offers a valuable and possibly unique laboratory in which to assess the impact of change and a distinctive opportunity for the refinement of current organisation-focused CM theory.

To stimulate bespoke enquiry and the identification of potential pan-domain implications, this paper therefore seeks to assess the application of CM theorising to the specific setting of the elite sport performance team. To meet this purpose, the paper initially discusses three challenges facing the acquisition of valid and comprehensive knowledge in the domain: first, an indicative review and critique of relevant $\mathrm{CM}$ and sport management literature is offered, highlighting the methodological limitations of previous research; second, the unique contextual challenges of the elite sport performance team environment are considered, with parallel appraisal of the need for tailored understanding; third, in light of the 
theoretical barriers to previous CM study, potentially parsimonious approaches are explored. To further guide the optimisation of future research and practice, the paper then concludes by identifying markers of successful change in elite sport performance teams before outlining directions for initial investigation. Reflecting the recent call for a greater understanding of CM at the micro-level (Cunningham, 2006a, 2006b), the paper is written from a psychological perspective (cf. Fletcher and Wagstaff, 2009; Henriksen et al., 2010; Weinberg and McDermott, 2002). Notably, the recent identification of culture change expertise as a key role of contemporary sport psychologists supports this position (cf. Fletcher and Arnold, 2011). Accordingly, the "micropolitics" (Potrac and Jones, 2009) of change are also considered throughout.

\section{Challenge I: Methodological Limitations of the CM Literature}

Given the importance of gaining an understanding of CM in the elite sport performance team, we present an indicative review evaluating current knowledge as a means for guiding initial enquiry and parallel theory development. Firstly, pertinent aspects from principally business-based CM research are considered before critical evaluation to demonstrate the limitations of this work. To further situate this paper within the literature, a similar depiction of relevant sport management research is also provided.

\section{Literature}

Acknowledging that management are habitually required to drive through change initiatives when an improvement in performance is required, much CM research has centred on providing practical frameworks for leaders seeking to develop a specific culture within their organisation (e.g., Kotter, 1996; Luecke, 2003; Mento et al., 2002; Price and Chahal, 2006; Ruvolo and Bullis, 2003; Wissema, 2001). Generally involving stages of planning, initiating, implementing and evaluating, researchers have also offered a multitude of measures considered necessary for effective change to occur. For example, creating shared 
expectations and vision (Luecke, 2003; Kotter, 1996), empowering employees (Ruvolo and Bullis, 2003), managing resistance (Erwin and Garman, 2009) and self reflection (Mento et al.) have, among others, been highlighted as vital processes, albeit often atheoretically. However, while numerous prescriptions have emerged from the literature, Balogun and Hope Hailey (2004) have stated that around 70\% of CM programs fail to elicit their intended performance transformations. This significant and commonly reported theme, we argue, may be a direct consequence of multiple methodological limitations which characterise the literature.

Certainly, one major criticism of the field is the historically non-empirical approach towards developing and testing theories and frameworks. Anecdotal prescriptions prevail, often derived from subjective experience (Ruvolo and Bullis, 2003) and arbitrary amalgamations of previous prescription (Price and Chahal, 2006; Mento et al., 2002), therefore raising doubt over the validity of the proffered advice. For example, while Ruvolo and Bullis (2003) provide (apparently) logically face-valid guidance derived from a U.S. military academy's failed culture change, no qualitative or quantitative analyses were used to arrive at their conclusions. Thus, such prescriptions appear to have obtained relative dominance in the field through unchallenged acceptance rather than confirmation of robustness.

A second area of contention is the predominant theoretical focus on process. This macro-level approach has reflected a rationalistic perspective for uncovering tangible change procedures, although it is significant that very few studies have tracked change drives in real time (Bamford and Forrester, 2003). Consider, for example, the work of Mento et al. (2002) who, from an amalgamation of lessons learned from previous change models filtered through practical experience, offer a definitive 12 step process for implementing change. The work of Luecke (2003) seems to offer an 'even better' plan, with nirvana accomplished in only “seven 
steps". Such prescriptions intuitively appeal to the needs of managers across the organisational setting, offering clear and unambiguous recipes for the achievement of success. The lack of empirical testing, however, prevents us knowing which, if any, are best or even correct. Furthermore, it appears both somewhat surprising and counterintuitive that so little attention has been devoted to understanding the perceptions of employees as the targets of change and how new processes impact upon them (Cunningham, 2006b; Devos, Buelens and Bouckenooghe, 2007; Driscoll and Morris, 2001; Neves and Caetano, 2006). In short, simplistic prescription is often offered without any clear evaluations of the methods through which it may operate, while advice seems driven by 'brand solutions' (e.g., Warriner, 2008) rather than any logically presented, evidence-based process.

Thirdly, little is empirically known about the actual mechanisms of change, for example, how do managers "instil trust" or "create a shared vision" (both common central pillars of any of the proposed systems)? The question of how appears to have been considered at a somewhat superficial level, often only through the prescription of broad directives (Devos et al., 2007). For instance, as a solution to resistance, Price and Chahal (2006) stipulate that resistors should be made part of the project: However their guideline to achieve this states that "if done with enough skill and with good employees, the implementation team can successfully use the doubters to improve the change process" (p. 249). The actual means by which resistors may be included remains unspecified, although recent research suggests that leaders may require a range of mechanistic abilities to manage change effectively, such as political bargaining (Hope, 2010; Potrac and Jones, 2009) and the utilisation of pivotal "tipping points" to enforce strategies (Kim and Mauborgne, 2003, p. 62). How, when and why such methods are selected and employed to optimally interact with employee/performer's cognitive-affective interpretations seems important for any 
conceptualisation to hold real ecological and predictive validity, as well as greater market worth.

Of final note, while employee/targets' psychological wellbeing is a significantly underrepresented line of enquiry, it should not be forgotten that the ultimate purpose for initiating change is to improve performance. Surprisingly (cf. Pettigrew et al., 2001; Wischnevsky and Damanpour, 2006), although business-based prescriptions have been widely distributed, the relationship between change processes, their psychological impact on change targets and performance outcomes has been largely ignored. Recognising that the ultimate goal for programs in the applied setting is to enhance, or certainly maintain, performance and outcome success, failure to comprehensively consider the changeperformance association is therefore another notable limitation of CM research.

\section{Sport Management Literature - The Off-Field Team}

As a consequence of modern elite sport teams' growing status as organisations and businesses (e.g., Gilmore and Gilson, 2007), the process of change has recently become a topic of notable interest in sports company management research. Indeed, similar to business-proffered guidance, successful evolution is considered to arrive from, among other aspects, the creation and acceptance of shared goals (Cunningham, 2009), relationships of trust (Smart and Wolfe, 2000) and empowerment of the targets of change (Amis et al., 2004). While not applying or testing specific CM prescription, these commonalities suggest that the construct may be both highly applicable and pertinent to the elite sport environment, where such process aims are common (cf. Collins et al., 2011; Dirks, 2000).

However, while comparable guidelines have emerged from research across both fields, sport management study has been equally and significantly afflicted by limitations in design and methodology, thereby diminishing its value for application in the elite sport performance team (and even sport company management itself). Firstly, research has again 
predominantly focused on the macro, system-level of change (Skinner et al., 1999; Zakus and Skinner, 2008), often in response to events in the external environment (Bloyce et al., 2008; Hanstad, 2008), rather than management-led initiatives focusing on the performers or performance per se. Second, there exists a widespread failure to consider how change is both successfully and unsuccessfully delivered at the individual level (cf. Cunningham, 2006a). Finally, and in stark contrast to the thrust of business-based CM investigation, research has often been occupied with theoretical explanations of previous change processes (e.g., Morrow and Idle, 2008; Thibault and Babiak, 2005) rather than the development of frameworks from which to direct future practice. For example, although Kelly (2008) highlighted the multifaceted nature of football management and mechanisms for optimal effectiveness, such as the appointment of trusted staff, no attempt was made to offer comprehensive guidance to individuals appointed into such demonstrably precarious positions.

\section{Challenge II: The Unique Features of the Elite Sport Performance Team Environment}

As suggested by the preceding review, for the most accurate depiction and prescription of elite sport performance team $\mathrm{CM}$, it is vital that enquiry considers and addresses the frailties of previous research. Similarly and further, beyond accepting the construct as a vital feature of the contemporary manager/head coaches' remit, a second equally important caveat is that it recognises and responds to the unique features of this highly complex and idiosyncratic environment.

Certainly, acknowledging contemporary elite sport's multidimensional focus on “performance, entertainment and financial profit" (Relvas et al., 2010, p. 166), central to this appeal for bespoke understanding is the argument that "for a coach to last, they must please the owner, management, players, fans, media, and be impermeable to the criticism that will occur when they fail” (Mielke, 2007, p. 107). Certainly, Potrac and Jones (2009, p. 223) describe sports coaching as a "power-ridden" activity whereby impression management is 
now vital in acquiring the time and support necessary to deliver change. As could be justifiably argued, the management of key internal and external stakeholders represents a crucial task in the effective delivery of change in any domain (Kihl et al., 2010). However, while the stakeholders highlighted by Mielke may also be implicated within organisationallevel change (more so in sports companies), it is the nature and extent to which the leader of the elite sport performance team must manage these relationships which challenges the predictive validity of current frameworks' application in the domain. For example, with some professional football, baseball and basketball teams paying their performers more than $£ 3.5$ million on average per year (Harris, 2011), it is evident that these individuals will hold significantly more power than the employees of many businesses in shaping the success (or failure) of a CM program. Acknowledging that the previous section implicitly considered players (and support staff) as the targets of change, however, the unique challenges posed by boards of directors, fans and the media will now be discussed in greater detail, with particular attention paid to the media due to its nature as both a key source and, on occasion, mediator of pressure. It is important to note that this consideration is not exhaustive and individual sports across different countries will in turn be characterised by further exclusive, fundamental challenges or constraints to CM practice, such as governing bodies and team's policies over player transfers (e.g., Dabscheck, 2006). Nonetheless, these apparently universal factors alone appear to suggest that present CM conceptions may be inappropriate for direct application in elite sport performance team setting.

\section{Pressure from the board.}

As in organisations, the performance of a manager/head coach in elite sport is critical to the success of the team and business. Dawson and Dobson (2002) have highlighted how variations in managerial performance can arise from an owner's inability to appropriately monitor activity due to its costly nature, and note that objectively measuring performance in 
business has been a long-standing problem. Sport, however, is matchless in this respect as assessment is both (apparently) directly and regularly possible. Specifically, boards of directors or owners are able to observe and evaluate the product derived from the management of all pertinent inputs in the form of competitive performances (Gould et al., 2002), which in sports such as football, rugby and basketball occurs weekly, if not even more frequently. The down side of this apparently 'informed' viewpoint is that these individuals are normally business people, and relatively naive on the mechanisms of the sport setting (Gilmore and Gilson, 2007). As a consequence, although culture change is not a swift process (Price and Chahal, 2006), the pressure on managers/head coaches to achieve instant and regular success provides a unique and conflicting circumstance. The tactical management of the board's perceptions in the face of initially inconsistent results may therefore be a critical factor for ensuring both success and longevity.

\section{Pressure from the fans.}

The psychology of fans' commitment to specific teams has received notable attention in the sport literature (Bee and Havitz, 2010; de Groot and Robinson, 2008) and may account in part for the pressure placed on managers to create and maintain a successful team. Indeed, Vallerand et al. (2003) have suggested that the enjoyable activities which constitute fandom become internalised into individuals' identities, and develop into a passion perceived as important and worthy of time and energy investment. As a consequence, the activities, decisions and performances of sports teams will have significant impacts upon fans (Wann and Schrader, 2000). Considering examples from football, Hutchins et al. (2009) have recently reported on the resistance of many English Premier League fans groups against the influxes of foreign capital into their clubs, while Nash (2001) has reported that supporter groups have been formed in direct reaction to the attitude and playing style of manager, significantly contributing to their eventual dismissal. Fans' perceptions consequently appear 
to be of great significance to the level and nature of support given to a manager, and gaining a favourable interpretation by this group may be a necessary mechanism for creating the most beneficial environment in which to deliver a program of change.

\section{Pressure from the media.}

The involvement and interest of the media in elite sport has grown exponentially in modern times as the volume and depth of coverage continues to push new boundaries. For example, in considering these requirements in relation to the elite sport manager/head coach, Carter (2007) provides a valuable account of the media's growing participation in English Premier League football. Specifically, he reports how managers' time is increasingly spent attending to media responsibilities. Significantly, Carter notes how Sir Alex Ferguson, longterm manager of Manchester United FC, contests that such appearances have lost a sense of their original purpose, instead becoming an exercise of character assassination. Indeed, data from our ongoing investigations lend support to this claim specific to elite sport performance team CM (Paper 1, 2011), with one interviewee who had managed at the top tier of contemporary British professional football reporting:

There is a reality you have to deal with and that reality is stressful for everybody...

[Then] there is a fantasy side and that's the media...you shouldn't get involved in that... "fabricated drama", that's what it is... [I]t makes it worse for you.

As mentioned earlier, time does not appear to be a commodity offered to elite sport performance team management (League Managers Association, 2010; Mielke, 2007) and, as a consequence, the media's consumption of this resource and the nature of their apparent intentions may provide a significant challenge to efforts to guide and drive through change.

While such recognition is important, however, it is also necessary to consider the media as not only a direct source of pressure but also as a mediator of pressure from other sources; specifically from the board and the fans. Regarding the former, Sisjord and 
Kristiansen (2008) have discussed how a positive media representation can assist with attracting sponsorship, a vital source of income for the boards of elite sport organisations. In similar fashion, Carter (2007) has highlighted how directors of football clubs have increasingly felt the requirement to have a manager in place that transmits a certain image of their club as a means of promotion of their product. Once again, data from our continuing research supports this assertion's relevance to elite sport performance team CM (Paper 2, 2011), as suggested by a player with notable experience in this environment:

[E]veryone reads the papers... [T]he media are the reason you're playing because they are writing about you and your sponsors want to see their name... You get money because of TV. I think [it] does play a big role... and how you manage [it] is a pretty important thing.

In this respect, media savvy and contact details of a good PR advisor are essential features of a consultant's armoury if a comprehensive support service is to be provided. At the very least, such individuals must be able to recognise when such support is needed, and act to encourage the beleaguered manager/head coach to seek help before all are sacked.

Perhaps more important, however, may be the relationship between the media and the fans. As discussed, fan dissatisfaction can ultimately cost a manager their job (Nash, 2001) and achieving positive perceptions through the media's portrayal appears a necessary measure for creating an optimal environment in which to conduct change. However, resulting from the shift from traditional objective accounts to sensationalist reporting (Carter, 2007), where certain journalists may thrive on "ammunition" (Reid, 2008, p. 67) from publicly stated comments to pursue attention-grabbing headlines and stories, achieving such a positive portrayal of one's character and competence may not appear as straight forward as it intuitively seems. Reflecting this trend, Pedersen, Miloch and Cothran (2006) have highlighted that the effective handling of the media and subsequent positive coverage can be 
of vital importance for achieving success, and of particular importance to leaders in their attempts to enforce their intended programs. This point strikes obvious resonance with the present paper and it appears that developing a favourable relationship with the media may be a key process in elite performance team CM.

\section{Summary}

As conveyed above, contemporary elite sport takes place in distinctive and complex surroundings which may well be unfamiliar to business. Specifically, as Boards of Directors are provided with regular opportunities to view the progress and outcomes of a manager's programme, it is imperative that the latter is equipped with strategies to allay the concerns of those 'above' when results and performance do not meet their expectations; or conversely protect against the formation of unrealistic goals when success is achieved. Of course, such political activity is also a requirement of managers in business (Hope, 2010). However, acknowledging this latter domain's tendency for quarterly, objective assessment (i.e., financial results: Benkraiem et al., 2009), the utility of organisation-derived CM frameworks for sporting performance is therefore significantly challenged. Similarly, while business managers are accountable to company shareholders, the level of indirect (via the media) and direct (via public team performances) contact performance team managers have with fans is incomparable. Finally, while effective PR activities are essential for successful business performance, companies are rarely exposed to daily comment by the printed and broadcast media (again, fuel for this fire is readily available through weekly performances).

In sum, the performance team manager's handling of all three of these groups and the dynamic interactions between them can be considered a vital activity for gaining the necessary time and space to deliver successful change. While sharing a degree of similarity with the conditions and contextual demands in business environments, the nature of these relationships are, however, fundamentally unique. 


\section{Challenge III: Theoretical Ambivalence}

Although a number of methodological contentions have been aimed at the nature and value of much $\mathrm{CM}$ research to date, perhaps the most concerning aspect of this work in both business and sports company management lies in the failure to be guided by robust theory. For example, it is unclear from which approach many business-derived CM frameworks are developed, while some work appears to prescribe guidelines based upon no discernable theoretical position whatsoever (e.g., Mento et al., 2002; Oakland and Tanner, 2007). Indeed, the previously dominant, planned and emergent approaches for understanding change have failed to achieve universal support regarding their explicative power, a point which may lie at the root of CM's predictive weakness (Bamford and Forrester, 2003). In sports company management research, this problem has manifested itself by historically atheoretical investigation (cf. Waddington and Skirstad, 2008) and, more recently, adoption of a number of approaches to best explain the change process (e.g., stakeholder theory: Morrow and Idle, 2008; institutional theory: Kikulis, 2000), sometimes even within the same work (Cunningham 2009; Slack and Hinings, 1992, Morrow and Idle). As a consequence, deeper debate regarding the suitability of theoretical underpinnings has recently been initiated (Smith, 2004) and it is now widely agreed that CM is a highly dynamic, nonlinear process (Graetz and Smith, 2010) which takes place within uncontrolled internal and external environments (By, 2005; Higgs and Rowland, 2010).

Subsequently, two approaches which may hold significant potential for enhancing our understanding and prescription of effective CM practice in the elite sport performance team are complexity theory (Cilliers, 2000) and decentred theory (Bevir and Rhodes, 2003). Of course, other accounts such as stakeholder theory (Kihl et al., 2010) and network theory (Rowley, 1997) may also hold significant value for unearthing the nature of successful (and unsuccessful) $\mathrm{CM}$ in this setting. However, acknowledging the effective application of 
decentred theory in a recent elite sport performance team CM investigation (Paper 2, 2011; see below) alongside complexity theory's: a) support in organisational domains (Morel and Ramanujam, 1999; Smith, 2004); and b) underpinning of pertinent theories (e.g., catastrophe theory: Hardy, 1996) and constructs (e.g. motor control: Ulrich, 2007) in sport psychology, an initial focus on these two approaches seems prudent.

\section{Complexity Theory as a Parsimonious Theoretical Approach}

As stated by Anderson (1999), complexity in organisational research is considered a structural variable characterising both the environment and organisation itself. From this viewpoint, organisations are seen as complex systems (Cilliers, 2000) because they consist of a large number of dynamically interacting elements (e.g., people, processes, history, context) whose interaction is nonlinear and produces emergent patterns of behaviour (e.g., adherence or resistance to change). As such, the behaviour of the system (e.g., successful performance) cannot be predicted from the inspection of its components alone but, instead, by the nature of the interaction of its elements (e.g., history, the mechanisms for change, and the management-employee relationship). CM research, by contrast, has traditionally focused on components of the organisation as orthogonal constructs, and complexity theory would attribute the high prevalence of program failure to this reason, namely the linear, hierarchical pathways which are inferred. As reported by Cilliers, the theory stresses that, in complex organisations, interactions determine system behaviour and, as such, relationships between the people of the organisation or team are vital. Furthermore, history and environmental context determine the nature of these interactions, unpredictable events are expected, and small events may have significantly large consequences and vice-versa. Finally, complex organisations are characterised by a structure on all scales with significant interaction between the components, while control is distributed throughout. Notably, all of these 
characteristics are common parameters of performance focused organisations such as professional sport teams and squads (and, of course, business).

Recent work by Theodoridis and Bennison (2009) has interestingly applied complexity theory to qualitatively explore retail location strategy in businesses. From this research, managers interviewed displayed different perceptions and understandings of complexity, with some remaining fixed on predetermined company policy (complexity absorbing) and others embracing opportunities presented by the internal and external environment (complexity adapting), which consequently impacted upon strategic decision making. Of further significant note, understanding complexity appeared a time dependent task, and the decision to dedicate time to environmental scanning was determined by the motivation to deal with it. Recalling that time is an increasingly rare commodity offered to managers/head coaches in elite sport, how complexity is approached in these pressurised environments may hold some power in explaining differential success and survival. Notably, Bowes and Jones (2006) have recently supported the application of complexity theory to aid understanding of sports coaching as they contend that the traditional rationalistic, linear assumptions upon which original theorising was based cannot fully explain the ceaseless planning, surveillance, evaluation and decision making that characterises the activity. Acknowledging that the management of change is an implicit function of the sports coach (Potrac and Jones, 2009; Jones and Wallace, 2005), the application of the theory to explain CM in elite sport performance teams therefore appears both valid and vindicated.

\section{Decentred Theory as a Parsimonious Theoretical Approach}

Similar to complexity theory in its conceptualisation of change as a dynamic and unpredictable process, decentred theory may also hold notable value in accurately accounting for the success and failure of CM programs. Rooted in the political governance literature (Bevir and Rhodes, 2003; Bevir and Richards, 2009a), this position rejects top-down 
approaches and argues that change is socially constructed by actors' whose beliefs are shaped by tradition and emerge in response to dilemmas. Understanding how change is effectively (and ineffectively) delivered is therefore promoted through a detailed appreciation of the specific context in which targets' decisions are made. Importantly, due to its focus on the action, reaction and negotiation of multiple individuals' motivations, it further proposes that "power appears wherever people interpret and respond to one another" and as such "every actor is constrained by the ways in which others act" (Bevir and Richards, 2009b, p. 140). Corresponding to recent findings by Hope (2010) which show how the political activities of an insurance company's middle managers allowed them to shape a change outcome and process to better fit their preferences, the analyses of decentred accounts "show how various actors restrict what others can do in ways that undermine the intentions of those others" (Bevir and Richards, 2009b, p. 140); or more pertinently, elucidate mechanisms which allow the leaders of change to manoeuvre their chosen systems, processes and procedures in ways which minimise the occurrence and impact of this contest.

Recognising that delivering change in sports teams (and businesses; Scott, 2010; MacAuley, Yue, Thurlow, 2010) has been identified as a predominantly social challenge (Potrac and Jones, 2009), initial enquiry in sport psychology has provided early support for decentred theory's application in the elite environment (Paper 2, 2011). Specifically, via the investigation of multiple stakeholders perspectives (including the management, players, support staff and CEO), it was discovered that the effective and efficient creation of a high performance culture in an English Premiership Rugby Union team was endogenously constructed through the subtle shaping of physical, structural and psychosocial contexts (for example: public visual displays of individual performance, generating competition for starting places, recruiting peer role models). Specifically, coupled with the management's key driving principle of staff ownership, stakeholders were liberated to make their own 
choices regarding the uptake and selection of performance-optimising behaviours and, due to the context created, were more likely to choose those congruent with sustained success. Interestingly, also critical to this program's success was the employment of various player feedback systems which regulated the inherent and incessant power flux between management and players in elite sport performance teams. Recognising Graetz and Smith's (2010) recent call for theoretical approaches which apply an "interactive mix of continuity and change", and the importance of managing this continuum to "guard against complacency and inertia" (p. 135), decentred theory may therefore hold significant promise for the investigation of change in this environment, and indeed that in comparable organisational settings.

\section{Markers of Successful Change in Elite Sport Performance Teams}

Upon conceptualising the elite sport performance team as a unique, complex and contested environment, coupled with the organisation-focused nature of current $\mathrm{CM}$ knowledge, the identification of potential markers of successful change are required to guide future research. Explicitly, as culture is a difficult concept to define and describe (Mamatoglu, 2008) we suggest that evidence will manifest itself on a number of levels; specifically in perceptions, processes and performances.

Specifically, if a change program is successful in the elite sport performance team this will be substantiated by high levels of coherency across a number of different actors' perceptions of management action and its efficacy (Paper 2, 2011). Certainly, as Stewart and Kringas (2003) note, perceptions have an important role in the measurement of change as different groups can view the change process in significantly disparate manners as a consequence of their diverse motivations. It can be intuitively assumed that, due to their role in leading the change and therefore holding the most accurate understanding of whether intended goals were met, managers/head coaches and their support staff will convey 
confirmatory perceptions of a successful change (Saka, 2003). It is notable however that almost all previous investigations to be completed in elite sport have focused exclusively on these groups (Gilmore and Gilson, 2007; Kelly, 2008; Schroeder, 2010; Vallée and Bloom, 2005) without any consideration of the performers themselves - the major focus of any CM initiative. Secondly, and in light of points raised earlier, successful change would also be manifest by coherent and consistently positive coverage in the media, particularly when it appears that there is an active choice made by the domain regarding the selective construction of reality through sensationalist reporting (Reid, 2008). Finally, compatible perceptions amongst boards of directors and fans will convey the achievement of successful performance levels and/or a beneficial portrayal in the media.

Regarding the process markers of successful change, suggested indicators come from both business and sport research. One such marker may be that of role clarity (Thelwell et al., 2008), a factor which has been shown to mediate the relationship between role efficacy and role performance effectiveness (Bray and Brawley, 2002). To illustrate, successful changes of culture in the performance team environment may be fostered by targets comprehensively understanding the new manager/head coach's expectations, thereby complimenting beliefs concerning their ability to perform accordingly under the new conditions. A second such marker may manifest itself in the presence of 360-degree feedback as a means for empowering performers to take active part in the change process (Cope et al. 2007). For example, Mamatoglu (2008) reported how the introduction of this process increased office workers' perceptions of a support and achievement culture. It is reasonable to assume that presence in performance team CM would therefore facilitate adherence to the change by ensuring that all stakeholders are provided with the opportunity to contribute and have their needs met, or at least discussed. In similar fashion, Lee et al. (2009) have recently reported how Sir Clive Woodward utilised performer-led performance 
debrief sessions to enhance performer understanding, ownership and learning. Notably and yet again, however, no evaluation of this marker was sought with the performers themselves. Beyond these two key processes, sport psychology knowledge would further suggest that productive coach-athlete relationships (Jowett \& Chaundy, 2004), team goal setting (Sénecal et al., 2008), performance feedback (Noblet and Gifford, 2002) mutual sharing (Holt and Dunn, 2006) and other team building activities (Bloom et al., 2003) will also reflect the prevalence of a high performing culture. Indeed, within this field, all have been shown to be correlated with performance-related variables (e.g., cohesion, collective efficacy) or enhanced performance itself.

Finally, although arguably of most importance, it is noted that successful change will be represented by an improved level of performance and/or outcome success, dependent on the goal orientation of the program. For example, evidence of this marker may be found in physical (e.g., body fat composition) and technical (e.g., passing accuracy) performance measures if focus is on the former. By definition, the members of high performing cultures will consistently adopt behaviours and practices which support sustained high performance (Schein, 2004). Accordingly, the persistent choice to engage in such activities will manifest itself in the results of such objective measures, provided that they are both related and sensitive to the intended culture (e.g., an emphasis on tackle success rate for a rugby team culture based upon determination and aggression). Last, but certainly not least, vital outcome markers will be reflected in enhanced win/loss ratios, points records and increased income due to playing more high profile matches and advancing further in competitions (Benkraiem et al., 2009). Additionally, further indicators of this kind may occur in the form of recognition given to performers and managers by the sport's governing body or sponsors (such as the 'player/manager of the month' awards in football). 
In accordance with the intentions of this paper, we have shown that a valid and rigorous assessment of elite performance team $\mathrm{CM}$ may hold significant implications for the development of bespoke theory and practice, and tangentially that within business and sport company management as well. As indicated, research to date has been significantly afflicted by inappropriate methodologies and unreliable theoretical underpinnings. As such, these limitations offer important guidance for future research into $\mathrm{CM}$ in the complex and unique environment of elite sport.

Based upon the major tenets of this paper, an initial line of enquiry should involve an empirical grounded theory approach (Bamford, 2008; Strauss and Corbin, 2008) to decipher the critical success factors, mechanisms and challenges of change specific to the elite sport performance environment. Ensuring that emerging data are unrestricted by present limited prescription and theory for inductive analysis (Rose and Jevne, 1993), such an approach would subsequently allow for a separate deductive analysis (Patton, 2002) to confirm (or disconfirm) the predicted disparity with current CM frameworks. It is noted that Schroeder (2010), recently failed to acknowledge deficiencies of previous investigation by uncritically and directly applying business-derived knowledge to guide his work into culture change. We argue, therefore, that an 'inductive then deductive' approach (cf. Edwards et al., 2002; Martindale et al., 2007) is best suited to validly and comprehensively determine the extent to which bespoke theory and practice is required.

Additionally, future research would further benefit from assessing agreement through the triangulation (Patton, 2002) of perception, process and performance markers as highlighted by the preceding section. Unlike the majority of CM research to date, this approach appears hugely significant for enhancing the external and predictive validity of theoretical understanding and applied practice. For this purpose, case studies lend themselves as particularly useful in obtaining a comprehensive understanding of the complexities of the 
change (Paper 2, 2011; Gilmore and Gilson, 2007). Once such enquiry has been extended by considering a number of successful and failed programs, opportunities should then present themselves to study in greater depth the identified crucial mechanisms for success. As suggested by the coverage in this paper, gaining a comprehensive understanding of the role of the media and how it can be effectively managed also appears to be of significant theoretical and applied value.

Furthermore, supported by the reported shifts in current pertinent literature (By, 2005; Smith, 2004), detailed evaluations of complexity theory and decentred theory as potentially parsimonious theoretical perspectives would also warrant considerable attention for the progression of a sport-specific theory and framework. Regarding the former, we see merit with a qualitative case study approach similar to that adopted by Theodoridis and Bennison (2009) in which elite team managers' understanding and responses to complexity are examined alongside their relationship with their decisions, actions and reactions in a specific CM process (ideally tracked in real time rather than retrospectively). Unlike this study, however, we propose that inductively analysed interviews with these figures, their support staff and performers are also triangulated with objective data encompassing the performance and outcome measures outlined above. Indeed, such consideration would help researchers determine the extent to which complexity adapting or absorbing is beneficial across a range of contexts and phases in the CM process.

In terms of decentred theory, reflecting the position's focus on the sociallyconstructed, power-governed nature of change, Bevir and Richards (2009a) encourage researchers to adopt ethnographic techniques which allow for individual "stories" to emerge free from the constraints of top-down assumptions. Amalgamating their guidance with further ethnographic directives in applied sport psychology (Krane and Baird, 2005), culture optimisation may therefore be examined through a mix of observation (participant or non- 
participant), field notes, research logs, reflexive journals, focus groups, texts and documents (e.g., media reports), visual data (e.g., training/match videos), questionnaires and, most crucially, unstructured or semi-structured interviews. Regarding the latter, Bevir and Richards (2009a) contend that the beliefs and actions of actors outside of the system in question (i.e., performance team environment members) must also be considered to provide a comprehensive picture of change. Accordingly, and reflecting the hypothesised power which they hold, interviews with CEOs, journalists and supporters group members will all enhance the validity of such work. To allow for the emergence of practically meaningful results, inductively analysed accounts can then be 'recentred'. Specifically, by assessing the coherence and consistency across key groups' perceptions (e.g., team management, support staff, performers, Board members, the media), critical success factors and key mechanisms can then be elucidated. We direct readers to the paper described above for a more detailed account of such a procedure (Paper 2, 2011).

Of final note, upon the identification of critical success factors and an understanding of the key mechanisms of elite performance team $\mathrm{CM}$, researchers will then be in a position to accurately track real-time change in the applied setting, something which has been relatively ignored in the organisational field. An action-research paradigm approach may offer a highly valuable and valid insight into the true nature of change in elite sport by "taking action and creating knowledge or theory about that action" (Coughlan and Coghlan, 2002, p. 220). Indeed, reflecting the task's highly context-specific nature, it seems logical to assert that this method of investigation will provide the most accurate picture of the nuances behind a programme's initiation, evolution, regulation and in some cases, termination.

\section{Conclusion}

To conclude, we believe that three key messages emerge from this review. Firstly, the pressure placed on contemporary managers/head coaches to deliver instantaneous 
performance-enhancing change in elite sport performance teams is becoming increasingly more common, intense and unforgiving (Bruinshoofd and ter Weel, 2003; League Managers Association, 2010). Indeed, while this paper includes a number of references to professional football and rugby (due the greater quantity and quality of work conducted in these sports), the rapid creation of high performing cultures is both a pan-sport (Mielke, 2007) and panprofession (e.g., manager: Lee et al., 2009; head coach: Jones et al., 2004; Olympic performance director: Fletcher and Arnold, 2011) issue. Accordingly, although contexts and the principles of best practice may vary across these variables and countries/continents, an understanding of $\mathrm{CM}$ is imperative to all areas of the elite performance sphere.

Secondly, while this may be the case, consultants and such leaders currently find themselves in a position whereby the little guidance that is available for effective and efficient action is ambiguous, unfounded and mostly inappropriate for this performance environment. Certainly, beyond the methodological and theoretical limitations of much work to date (which challenge prescribed frameworks' utility even in business), the ability of present $\mathrm{CM}$ theorising to account for the unique and dynamic power relations and external influences which characterise elite sport is highly debatable.

Finally, and in direct relation to the preceding conclusions, there therefore exists a real and urgent need to develop a valid and reliable sport-specific CM theory and framework upon which to base practice. For such purposes, it would appear that research in elite sport would be wise to consider the utility of complexity theory and decentred theory as two potentially parsimonious approaches. Indeed, initial support for both in organisational and elite sport research domains (Bowes and Jones, 2006; Paper 2, 2011; Smith, 2004) justifies their initial prioritisation over others such as stakeholder and network theory (although we encourage investigation of all four, and others). 
In sum, CM is both an applicable and highly pertinent construct for the optimisation of elite sport team performance. Specifically, through its focus on delivering new practices which enable short-term survival and long-term success in highly dynamic environments (By, 2005), the process' alignment with incoming managers' intentions to establish and sustain a high performing culture is strikingly clear. Accordingly, and recalling elite sport's ability to act as a mirror and laboratory for the advancement of organisational understanding and practice, addressing the gaps described above represents an important need for the leaders of change, their employers, and of course academics and consultants of CM. Indeed, we envisage that enquiry through, of and for elite sport performance teams will provide crucial lessons for both sport and business. 


\section{References}

Aoyagi, M. W., Cox, R. H. and McGuire, R. T. (2008) Organisational citizenship behaviour in sport: Relationships with leadership, team cohesion, and athlete satisfaction, Journal of Applied Sport Psychology, 20(1), pp. 25-41.

Amis, J., Slack, T. and Hinings, C. R. (2004) Strategic change and the role of interests, power and organisational capacity, Journal of Sport Management, 18(2), pp. 158-198.

Anderson, P. (1999) Complexity theory and organisation science, Organisation Science, 10(3), pp. 216-232.

Balogun, J. and Hope Hailey, V. (2004) Exploring Strategic Change (2nd ed.), London: Prentice Hall.

Bamford, D. (2008) The use of grounded theory in change management research, Journal of Change Management, 8(2), pp. 111-121.

Bamford, D. and Daniel, S. (2005) A case study of change management effectiveness within the NHS, Journal of Change Management, 5(4), pp. 391-406.

Bamford, D. R. and Forrester, P. L. (2003) Managing planned and emergent change within an operations management environment, International Journal of Operations and Production Management, 23(5), pp. 546-564.

Bee, C. C. and Havitz, M. E. (2010) Exploring the relationship between involvement, fan attraction, psychological commitment, and behavioural loyalty in a sports spectator context, International Journal of Sports Marketing and Sponsorship, 11(2), pp. 140157.

Benkraiem, R., Louhichi, W. and Marques, P. (2009) Market reaction to sporting results: The case of European listed football clubs, Management Decision, 47(1), pp. 100-109.

Bevir, M. and Rhodes, R. A. W. (2003) Interpreting British Governance, London: Routledge. 
Bevir, M. and Richards, D. (2009a) Decentring policy networks: A theoretical agenda, Public Administration, 87(1), pp. 3-14.

Bevir, M. and Richards, D. (2009b) Decentring policy networks: Lessons and prospects, Public Administration, 87(1), pp. 132-141.

Bloom, G. A., Stevens, D. E. and Wickwire, T. L. (2003) Expert coaches' perceptions of team building, Journal of Applied Sport Psychology, 15, pp. 129-143.

Bloyce, D., Smith, A., Mead, R. and Morris, J. (2008) 'Playing the game (plan)': A figurational analysis of organisational change in sports development in England, European Sport Management Quarterly, 8(4), pp. 359-378.

Bowes, I. and Jones, R. L. (2006) Working at the edge of chaos: Understanding head coaching as a complex, interpersonal system, The Sport Psychologist, 20(2), pp. 235245.

Bray, S. R. and Brawley, L. R. (2002) Role efficacy, role clarity, and role performance effectiveness, Small Group Research, 33(2), pp. 233-253.

Bruinshoofd, A. and ter Weel, B. (2003) Manager to go? Performance dips reconsidered with evidence from Dutch football, European Journal of Operational Research, 148(2), pp. 233-246.

By, R. T. (2005) Organisational change management: A critical review, Journal of Change Management, 5(4), pp. 369-380.

By, R. T., Diefenbach, T. and Klarner, P. (2008) Getting organizational change right in public services: The case of European higher education, Journal of Change Management, 8(1), pp. 21-35.

Carter, N. (2007) 'Managing the media': The changing relationship between football managers and the media, Sport in History, 27(2), pp. 217-240. 
Cilliers, P. (2000) What can we learn from a theory of complexity? Emergence, 2(1), pp. 2333.

Collins, D. (2008) Strange bedfellows: Why sport and exercise psychology? Sport \& Exercise Psychology Review, 5(2), pp. 57-59.

Collins, D., Button, A. and Richards, H. (2011) Performance psychology: A practitioner's guide, Oxford: Elsevier

Cope, C. J., Eys, M. A., Schinke, R. J. and Bosselut, G. (2007) Coaches' perspectives of a negative informal role: The 'cancer' within sport teams, Journal of Applied Sport Psychology, 22, pp. 420-436.

Coughlan, P. and Coghlan, D. (2002) Action research for operations management, International Journal of Operations and Production Management, 22(2), pp. 220240.

Cunningham, G. B. (2006a) Examining the relationships among coping with change, demographic dissimilarity and championing behaviour, Sport Management Review, 9(3), pp. 253-270.

Cunningham, G. B. (2006b) The relationships among commitment to change, coping with change, and turnover intentions, European Journal of Work and Organisational Psychology, 15(1), pp. 29-45.

Cunningham, G. B. (2009) Understanding the diversity-related change process: A field study, Journal of Sport Management, 23(4), pp. 407-428.

Dabscheck, B. (2006) The globe at their feet: FIFA's new employment rules - II. Sport in Society, 9(1), 1-18.

Dawson, P. and Dobson, S. (2002) Managerial efficiency and human capital: an application to English association football, Managerial and Decision Economics, 23(8), pp. 471486. 
Dirks, K. T. (2000) Trust in leadership and team performance: Evidence from NCAA basketball, Journal of Applied Psychology, 85(6), pp. 1004-1012.

Devos, G., Buelens, M. and Bouckenooghe, D. (2007) Contribution of content, context, and process to understanding openness to organisational change: Two experimental simulation studies, The Journal of Social Psychology, 147(6), pp. 607-629.

de Groot, M. and Robinson, T. (2008) Sport fan attachment and the psychological continuum model: A case study of an Australian football league fan, Leisure, 32(1), pp. 117-138.

Driscoll, A. and Morris, J. (2001) Stepping out: Rhetorical devices and culture change management in the UK civil service, Public Administration, 79(4), pp. 803-824.

Edwards, T., Kingston, K., Hardy, L. and Gould, D. (2002) A qualitative analysis of catastrophic performances and the associated thoughts, feelings and emotions, The Sport Psychologist, 16(1), pp. 1-19.

Erwin, D. G. and Garman, A. N. (2009) Resistance to organisational change: linking research and practice, Leadership and Organisation Development Journal, 31(1), pp. 39-56.

Fletcher, D. and Arnold, R. (2011) A qualitative study of performance leadership and management in elite sport, Journal of Applied Sport Psychology, 23(2), pp. 223-242.

Fletcher, D. and Wagstaff, C. R. D. (2009) Organisational psychology in elite sport: Its emergence, application and future, Psychology of Sport and Exercise, 10(4), pp. 427434.

Gilmore, S. and Gilson, C. (2007) Finding form: Elite sports and the business of change, Journal of Organisational Change Management, 20(3), pp. 409-428.

Gould, D., Guinan, D., Greenleaf, C. and Chung, Y. (2002) A survey of U.S. Olympic coaches: Variables perceived to have influenced athlete performances and coach effectiveness, The Sport Psychologist, 16(3), pp. 229-250. 
Graetz, F. and Smith, A. T. C. (2010) Managing organisational change: A philosophies of change approach, Journal of Change Management, 10(2), pp. 135-154.

Guzmán, I. (2006) Measuring efficiency and sustainable growth in Spanish football teams, European Sport Management Quarterly, 6(3), pp. 267-287.

Hardy, L. (1996) Testing the predictions of the cusp catastrophe model of anxiety and performance, The Sport Psychologist, 10(2), pp. 140-156.

Hanstad, D. G. (2008) Drug scandal and organisational change within the international ski federation: A figurational approach, European Sport Management Quarterly, 8(4), pp. 379-398.

Harris, N. (2011) Global Sports Salaries Survey 2011. Retrieved from http://sports.espn.go.com/espn/news/story?id=6354899

Henriksen, K., Stambulova, N. and Roessler, K. K. (2010) Holistic approach to athletic talent development environments: A successful sailing milieu, Psychology of Sport and Exercise, 11(3), pp. 212-222.

Higgs, M. and Rowland, D. (2010) Emperors with clothes on: The role of self-awareness in developing effective change leadership, Journal of Change Management, 10(4), pp. 369-385.

Holt, N. L. and Dunn, J. G. H. (2006) Guidelines for delivering personal-disclosure mutualsharing team building interventions, The Sport Psychologist, 20, pp. 348-367.

Hope, O. (2010) The politics of middle management sensemaking and sensegiving, Journal of Change Management, 10(2), pp. 195-215.

Hutchins, B., Rowe, D. and Ruddock, A. (2009) "It's fantasy football made real": Networked media sport, the internet, and the hybrid reality of MyFootballClub, Sociology of Sport Journal, 26(1), pp. 89-106. 
Jones, G. (2002) Performance excellence: A personal perspective on the link between sport and business, Journal of Applied Sport Psychology, 14(4), pp. 268-281.

Jones, R. L., Armour, K. M. and Potrac, P. (2004) Sports coaching cultures: From practice to theory. London: Routledge.

Jones, R. L. and Wallace, M. (2005) Another bad day at the training ground: coping with ambiguity in the coaching context, Sport, Education and Society, 10(1), pp. 119-134.

Jowett, S. and Chaundy, V. (2004) An investigation into the impact of coach leadership and coach-athlete relationship on group cohesion, Group Dynamics: Theory, Research and Practice, 8(4), pp. 302-311.

Kelly, S. (2008) Understanding the role of the football manager in Britain and Ireland: A Weberian approach, European Sport Management Quarterly, 8(4), pp. 399-419.

Kihl, L. A., Leberman, S. and Schull, V. (2010) Stakeholder constructions of leadership in intercollegiate athletics, European Sport Management Quarterly, 10(2), pp. 241-275.

Kikulis, L. M. (2000) Continuity and change in governance and decision making in national sport organisations: Institutional explanations, Journal of Sport Management, 14(4), pp. 293-320.

Kim, W. Chan. and Mauborgne, R. (2003) Tipping point leadership, Harvard Business Review, 81(4), pp. 60-69.

Kotter, J. P. (1996) Leading Change, Boston, MA: Harvard Business School Press.

Kotter, J. P. and Heskett, J. L. (1992) Corporate Culture and Performance, New York: Free Press.

League Managers Association (2010) LMA end of season statistics 2010. Retrieved April 21st, 2011, from http://www.leaguemanagers.com/news/news-6585.html 
Lee, S., Shaw, D. J. and Chesterfield, G. (2009) Reflections from a world champion: an interview with Sir Clive Woodward, director of Olympic performance, the British Olympic Association, Reflective Practice, 10(3), pp. 295-310.

Luecke, R. (2003) Managing Change and Transition, Boston, MA: Harvard Business School Press.

MacAuley, K. D., Yue, A. R. and Thurlow, A. B. (2010) Ghosts in the hallways: Unseen actors and organisational change, Journal of Change Management, 10(4), pp. 335346.

Mamatoglu, N. (2008) Effects on organisational context (culture and climate) from implementing a 360-degree feedback system: The case of Arcelik, European Journal of Work and Organisational Psychology, 17(4), pp. 426-449.

Martindale, R. J. J., Collins, D. and Abraham, A. (2007) Effective talent development: The elite head coach perspective in UK sport, Journal of Applied Sport Psychology, 19(2), pp. 187-206.

Mento, A. J., Jones, R. M. and Dirndorfer, W. (2002) A change management process: Grounded in both theory and practice, Journal of Change Management, 3(1), pp. 4559.

Mielke, D. (2007) Coaching experience, playing experience and coaching tenure, International Journal of Sports Science and Coaching, 2(2), pp. 105-108.

Moran, J. W. and Brightman, B. K. (2001) Leading organizational change, Career Development International, 6(2), pp. 111-118.

Morel, B. and Ramanujam, R. (1999) Through the looking glass of complexity: The dynamics of organizations as adaptive and evolving systems, Organization Science, 10(3), pp. 278-293. 
Morrow, S. and Idle, C. (2008) Understanding change in professional road cycling, European Sport Management Quarterly, 8(4), pp. 315-335.

Nash, R. (2001) English football fan groups in the 1990's: Class, representation and fan power, Soccer and Society, 2(1), pp. 39-58.

Neves, P. and Caetano, A. (2006) Social exchange processes in organisational change: the roles of trust and control, Journal of Change Management, 6(4), pp. 351-364.

Noblet, A. J. and Gifford, S. M. (2002) The sources of stress experienced by professional Australian Footballers, Journal of Applied Sport Psychology, 14(1), 1-13.

Oakland, J. S. and Tanner, S. (2007) Successful change management, Total Quality Management, 18(1-2), pp. 1-19.

Olusoga, P., Butt, J., Hays, K. and Maynard, I. (2009) Stress in elite sports coaching: Identifying stressors, Journal of Applied Sport Psychology, 21(4), pp. 442-459.

Paper 1 (2011) Manuscript in preparation.

Paper 2 (2011) Manuscript submitted for publication.

Patton, M. Q. (2002) Qualitative Research \& Evaluation Measures, London: Sage, Thousand Oaks.

Pedersen, P. M., Miloch, K. S. and Cothran, D. J. (2006) Increasing program exposure through enhanced media relations, Journal of Physical Education, Recreation and Dance, $77(7)$, pp. 10

Pettigrew, A. M., Woodman, R. W. and Cameron, K. S. (2001) Studying organisational change and development: Challenges for future research, Academy of Management Journal, 44(4), pp. 697-713.

Potrac, P. and Jones, R. (2009) Power, conflict and cooperation: Toward a micropolitics of head coaching, Quest, 61(2), pp. 223-236. 
Price, A. D. F. and Chahal, K. (2006) A strategic framework for change management, Construction Management and Economics, 24(3), pp. 237-251.

Reid, I. A. (2008) 'An outsider in our midst': narratives of Neil Lennon, soccer and ethnoreligious bigotry in the Scottish press, Soccer and Society, 9(1), pp. 64-80.

Relvas, H., Littllewood, M., Nesti, M., Gilbourne, D. and Richardson, D. (2010) Organisational structures and working practices in elite European professional football clubs: Understanding the relationship between youth and professional domains, European Sport Management Quarterly, 10(2), pp. 165-187.

Rose, J. and Jevne, R. F. J. (1993) Psychological processes associated with athletic injuries, The Sport Psychologist, 7(3), pp. 309-328.

Rowley, T. J. (1997) Moving beyond dyadic ties: a network theory of stakeholder influences, Academy of Management Review, 22, pp. 887-910.

Ruvolo, C. M. and Bullis, R. C. (2003) Essentials of culture change: Lessons learned the hard way, Consulting Psychology Journal: Practice and Research, 55(3), pp. 155-168.

Saka, A. (2003) Internal change agents' view of the management of change problems, Journal of Organisational Change Management, 16(5), pp. 480-496.

Schein, E. H. (2004) Organizational culture and leadership (3rd ed.), San Francisco: JosseyBass.

Schroeder, P. J. (2010) Changing team culture: The perspectives of ten successful head coaches, Journal of Sport Behaviour, 32(4), pp. 63-88.

Scott, R. W. (2010) Reflections: The past and future research on institutions and institutional change, Journal of Change Management, 10(1), pp. 5-21.

Sénecal, J., Loughead, T. M. and Bloom, G. A. (2008) A season-long team-building intervention: Examining the effect of team goal setting on cohesion, Journal of Sport \& Exercise Psychology, 30, pp. 186-199. 
Sisjord, M. K. and Kristiansen, E. (2008) Serious athletes or media clowns? Female and male wrestlers' perceptions of media constructions, Sociology of Sport Journal, 25(3), pp. $350-368$.

Skinner, J., Stewart, B. and Edwards, A. (1999) Amateurism to professionalism: Modelling organisational change in sporting organisations, Sport Management Review, 2(2), pp. 173-192.

Smart, D. L. and Wolfe, R. A. (2000) Examining sustainable competitive advantage in intercollegiate athletics: a resource-based view, Journal of Sport Management, 14(2), pp. $133-153$.

Smith, A. T. C. (2004) Complexity theory and change management in sport organisations, Emergence: Complexity and Organisation, 6(1-2), pp. 70-79.

Smith, A. T. C. and Stewart, B. (2010) The special features of sport: A critical revisit, Sport Management Review, 13(1), pp. 1-13.

Stensaker, I. G. and Langley, A. (2010) Change management choices and trajectories in a multidivisional firm, British Journal of Management, 21(1), pp. 7-27.

Stewart, J. and Kringas, P. (2003) Change management - strategy and values in six agencies from the Australian Public Service, Public Administration Review, 63(6), pp. 675688.

Strauss, A. and Corbin, J. (2008) Basics of qualitative research: Techniques and procedures for developing grounded theory ( $3^{\text {rd }}$ ed.), London: Sage.

Thelwell, R. C., Weston, N. J. V., Greenlees, I. A. and Hutchings, N. V. (2008) Stressors in elite sport: A coach perspective, Journal of Sports Sciences, 26(9), pp. 905-918

Theodoridis, C. and Bennison, D. (2009) Complexity theory and retail location strategy, The International Review of Retail, Distribution and Consumer Research, 19(4), pp. 389403. 
Thibault, L. and Babiak, K. (2005) Organisational changes in Canada's sport system: Toward an athlete-centred approach, European Sport Management Quarterly, 5(2), pp. 105132.

Ulrich, B. (2007) Motor development: Core curricular concepts, Quest, 59, pp. 77-91.

Vallée, C. N. and Bloom, G. A. (2005) Building a successful University program: Key and common elements of expert coaches, Journal of Applied Sport Psychology, 17(3), pp. 179-196.

Vallerand, R. J., Blanchard, C., Mageau, G. A., Koestner, R., Ratelle, C., Léonard, M.,... Marsolais, J. (2003) Les passions de l'âme: On obsessive and harmonious passion, Journal of Personality and Social Psychology, 85(5), pp. 756-767.

Waddington, I. and Skirstad, B. (2008) Theoretical approaches to change in sports organisations, European Sport Management Quarterly, 8(4), pp. 311-313.

Wann, D. L. and Schrader, M. P. (2000) Controllability and stability in the self-serving attributions of sport spectators, Journal of Social Psychology, 140(2), pp. 160-168.

Warriner, K. (2008) Demystifying the challenge of change, The Lane4 Journal of Excellence, pp. 11-20. Retrieved April 21 ${ }^{\text {st }}$, 2011, from http://www.lane4performance.com/Research-Published-Research.html?page=2

Weinberg, R. and McDermott, M. (2002) A comparative analysis of sport and business organisations: Factors perceived critical for organisational success, Journal of Applied Sport Psychology, 14(4), pp. 282-298.

Wischnevsky, J. D. and Damanpour, F. (2006) Organisational transformation and performance: An examination of three perspectives, Journal of Managerial Issues, 18(1), pp. 104-128.

Wissema, J. G. (2001) Offensive change management with the step-by-step method, Journal of Change Management, 1(4), pp. 332-343. 
Zakus, D. W. and Skinner, J. (2008) Modelling organisational change in the International Olympic committee, European Sport Management Quarterly, 8(4), pp. 421-442. 